the references to these plates, and the photographic brightness of the star.

(2) Catalogue of Spectra of Faint Stars.-This work resembles the preceding, but is much more extensive. The same instrument is used, but each region has an exposure of an hour, the rate of the clock being such that the width of the spectrum will be as before $0^{\circ} \mathrm{I} \mathrm{cm}$. Many stars of the ninth magnitude will thus be included, and nearly all brighter than the eighth. In one case, over three hundred spectra are shown on a single plate. This work has been carried on only in the intervals when the telescope was not needed for other purposes. 99 plates have however been obtained, and on these 4442 spectra have been measured. It is proposed to complete the equatorial zones first, gradually extending the work northward. In all, 15,729 spectra of bright and faint stars have been measured.

(3) Detailed Study of the Spectra of the Brighter Stars.This work has been carried on with the II-inch photographic telescope used by Dr. Draper in his later researches. A wooden observatory was constructed about 20 feet square. This was surmounted by a dome having a clear diameter of 18 feet on the inside. The dome had a wooden frame, sheathed and covered with canvas. It rested on eight cast-iron wheels, and was easily moved by hand, the power being directly applied. Work was begun upon it in June, and the first observations were made with the telescope in October. Two prisms were formed by splitting a thick plate of glass diagonally. These gave such good results that two others were made in the same way, and the entire battery of four prisms is ordinarily used. The safety and convenience of handling the prisms is greatly increased by placing them in square brass boxes, each of which slides into place like a drawer. Any combination of the prisms may thus be employed. As is usual in such an investigation, a great variety of difficulties have been encountered, and the most important of them have now been overcome.

(4) Faint Stellar Spectra.-The 28-inch reflector will be used for the study of the spectra of the faint stars, and also for the fainter portions near the ends of the spectra of the brighter stars. The form of spectroscope mentioned above, in which the collimator and slit are replaced by a concave lens, will be tried. The objects to be examined are, first, the stars known to be variable, with the expectation that some evidence may be afforded of the cause of the variation. The stars whose spectrum is known to be banded, to contain bright lines, or to be peculiar in other respects, will also be examined systematically. Experiments will also be tried with orthochromatic plates and the use of a coloured absorbing medium, in order to photograph the red portions of the spectra of the bright stars. Quartz will also be tried to extend the images towards the ultra-violet.

(5) Absorption Spectra.-The ordinary form of comparison spectrum cannot be employed on account of the absence of a slit. The most promising method of determining the wave-lengths of the stellar spectra is to interpose some absorbent medium. Experiments are in progress with hyponitric fumes and other substances. A tank containing one of these materials is interposed, and the spectra photographed through it. The stellar spectra will then be traversed by lines resulting from the absorption of the media thus interposed, and, after their wavelengths are once determined, they serve as a precise standard to which the stellar lines may be referred. The absorption-lines of the terrestrial atmosphere would form the best standard for this purpose if those which are sufficiently fine can be fhotographed.

(6) Wave-Lengths. - The determination of the wavelengths of the lines in the stellar spectra will form an important part of the work which has not yet been begun. The approximate wave-lengths can readily be found from a comparison with the solar spectrum, a sufficient number of solar lines being present in most stellar spectra. As a difference of one ten-millionth of a millimetre in wavelength exceeds half a millimetre in Figs. 5 and 6 of the accompanying plate, the readings may be made with considerable accuracy by a simple inspection. For greater precision special precautions are necessary on account of the deviation caused by the approach and recession of the stars. The deviation found by Dr. Huggins in the case of Sirius would correspend to a change in the position of the lines of Figs. 5 and 6 of about half a millimetre. If, then, satisfactory results are obtained in the preceding investigation, the motion of the stars can probably be determined with a high degree of precision. The identification of the lines with those of terrestrial substances will of course form a part of the work, but the details will be considered subsequently.

From the above statement it will be seen that photographic apparatus has been furnished on a scale unequalled elsewhere. But what is more important, Mrs. Draper has not only provided the means for keeping these instruments actively employed, several of them during the whole of every clear night, but also of reducing the results by a considerable force of computers, and of publishing them in a suitable form. A field of work of great extent and promise is open, and there seems to be an opportunity to erect to the name of Dr. Henry Draper a memorial such as heretofore no astronomer has received. One cannot but hope that such an example may be imitated in other departments of astronomy, and that hereafter other names may be commemorated, not by a needless duplication of unsupported observatories, but by the more lasting monuments of useful work accomplished. EDWARD C. PICKERING,

Director of Harvard College Observatory. Cambridge, Mass., U.S.A., March I, I887.

\section{SCIENCE AND GUNNERY.}

\section{I.}

I the last lecture which Prof. Tyndall delivered at the Royal Institution, he expressed a doubt as to whether extensive reading and study had not a tendency to hamper original genius, whether doctrines handed down for generations as articles of faith, which it would be heresy to dispute, had not materially checked the progress of science. Had he wished to illustrate his theory, he could not have had better examples than are to be found in the administration of our naval and military systems. It has been a reproach to us, as by far the greatest maritime nation of the world, that we have no School of Shipbuilding, that, until quite recently, naval officers have had no instruction except such as they could get in the practical execution of their duties, and no method existed of testing their knowledge except such rough-and-ready examinations as their superior officers could administer. Yet. under these seeming disadvantages the Navy and the merchant service bave kept in the forefront of progress, and have adopted all the newest discoveries of science, or of practical skill, as fast as they have been brought to light.

On the other hand, the officers of Artillery and Engineers have long been considered as belonging to the scientific branches of the service ; they have been regularly trained in schools in which theory and history have been taught, and the consequence seems to be that it is most difficult to make the departments with which they are connected move with the times. How else can it be explained that we have adhered to wrought iron as a material for guns, and to muzzle-loaders, long after nations esteemed semibarbarous have used steel and constructed breechloaders? or how can we explain the waste of millions in constructing fortifications of patterns long obsolete, and which show no more originality than that exhibited in using 
in some places iron instead of stone to resist the greater energy of modern projectiles? Not but that there have been many men both in the Artillery and Engineers who have seen the unfitness of what we have been doing, and have energetically protested against it, but they have not had force enough at the War Office to overcome the inertia due to the complacency derived from, perhaps, just pride in a profound knowledge of books.

We do not go quite the length of Dr. Tyndall's opinions, though we admit that there is much truth in them; we recognise the difficulty of teaching in advance, if we may use the expression; but there can be no doubt that precedent and routine have much to answer for, and account for the reluctance of Professors to admit that many of the old methods of fortification and artillery are as dead and useless as the matchlock or the old castle. Besides these considerations derived from experience of the services, we have the fact that most of the original inventions in the construction of guns and carriages have been the work of civil engineers and mechanics, who have been unhampered by precedent and unchecked by authority, and this circumstance must be our apology, as a man-professional paper, for devoting some space to a discustion of the present state of the science of fortification, especially with regard to our own coast defences.

It cannot be disputed, in the first place, that the projectiles delivered by modern guns are distinguished by greatly extended range, by much greater accuracy of flight, by immensely greater weight and destructive power, and by increased rapidity and precision of firing; but on the other hand it must also be admitted that in fighting at long ranges there will be greater waste of ammunition, and that, to put it plainly, excitement and fright go far to neutralise the advantages gained by our improved weapons, and that, consequently, defensive works should be planned so as to give the utmost possible security and sense of safety to the garrison. It is only necessary to study the records of recent naval actions, such as those during the War of Secession in the United States, the bombardment of Alexandria, or fights with dense hordes of savages in the Soudan and elsewhere, to be satisfied of the fact that the amount of destruction caused is small compared with the terrific fire employed. In the case of attack by artillery on shore the results are not so unsatisfactory, the steadiness of the platform, the accurately known range, the immovability of the gun and object fired at, the fact that the best and steadiest soldiers can be selected to aim, and that any nervousness in the gunner does not unsteady the gun, makes the fire of field and siege artillery approach much more nearly to what can be attained in times of peace; but even then, as in the Navy, smartness and rapidity of fire, the descendants of time-honoured drill, aggravated by excitement, are often the cause of a lamentable sacrifice of accuracy.

To make good shooting it is imperative that the men should be reasonably safe, especially against wholesale slaughter such as is caused by the bursting of a shell in a casemate, and this necessity is all the more imperative at the beginning of a war, when most of the soldiers have as yet never heard the shriek of a shell at their ears, or witnessed its terrifying effects. The shooting should be slow and deliberate in order to be effective, the result of each shot should be ascertained, for it must be remembered that the costly charges now fired are no more effective than those of the old smooth-bore artillery unless they reach their destination.

Next, the advantage of long range, accuracy, and rapidity of fire is in a great degree neutralised by the dense volumes of smoke produced by the modern large charges of powder, and although smoke may prove a valuable protection against the accuracy of an enemy's fire, it undoubtedly limits one's own offensive power except under certain conditions to which we will refer again.

In the last place, it may be conceded that an object which you cannot see you cannot aim at; that to be invisible is better than to be protected by armour, and this desirable condition of safety is easily attained in the case of coast defences against ships, because a ship, being always more or less in motion, even when at anchor, can never mark accurately any object of which it can get only an occasional peep. Thus, at the bombardment of Alexandria, one of the undoubted advantages on the side of the defenders was that some of their batteries were not to be distinguished from the irregular features of the rocky coast, and their presence could only be detected by the puffs of smoke from their guns. Even the old-established rules relating to fortifications admit the necessity of concealment; the greatest secrecy is maintained as to the internal economy of forts; access to them cannot be obtained without great difficulty, although we believe that little or nothing is to be gained by such precautions. What should be concealed is the fort itself, and its construction should be of such a nature that the fire of an enemy could not reach the essential mountings and stores it is intended to protect. Even Nature teaches us a lesson in this respect : animals liable to be the prey of others construct their nests of a form and colour and dispose of them so as to be invisible from a short distance, and even the colour of their plumage or their fur is made to assimilate to the tints which surround them; and the tactics they employ when in danger are to lie still so as not to attract attention.

The propositions which we have laid down, and which we do not imagine can be disputed, are of a nature to condemn at once the old systems of fortification, which appear to us to be specially contrived to afford the peculiar advantages which an enemy would desire; nor are alternative and more rational methods wanting, for as far back as May 7, 1869, at the Royal Institution of Great Britain, a paper, describing a new system of coast fortification calculated to meet the changes in artillery and the modern conditions of naval attack, was read by Colonel Moncrieff. In that paper the principle of concealment was laid down, the manner of carrying out the system explained, and the first workable disappearing gun-carriage, which made the realisation of the principles enunciated practicable, was described.

The time for bringing the matter before the public was also opportune, because the loan which had been contracted for strengthening the defences of the country had not all been expended, while the advance in the range and power of artillery was beginning to be fully realised. The authorities, however, were blind to the principles involved; they accepted, indeed, the disappearing gun, but they rejected the system of which it was only a detail. It would have been better had they accepted the system, and rejected the gun-carriage. The consequence of this incredible want of common-sense and discernment has been that a series of misapplications of the methods advocated by Colonel Moncrieff have been perpetrated by the War Office, as, for example, at Milford Haven, Hubberston, Newhaven, Popston, \&c. In some of these forts the emplacements for the disappearing guns are actually formed on the top of casemates, crowded into the most conspicuous positions possible.

Those who have had an opportunity of witnessing the trials of guns and their carriages at the Royal Arsenal; must have been struck with the marvellous resistance which a heap of earth opposes to the proof shots fired into it. An insignificant mound stops the heaviest projectiles fired at a few yards' range from the most powerful guns loaded with proof charges, the mound remains uninjured, though daily subjected to blows which would soon wreck any structure made of the most solid materials. The Moncrieff system is specially adapted to take advantage of this stubborn resistance of earth, and that circumstance alone should have commended it to the official mind long years ago, especially as, in addition, the necessarily slight 
inclination of the slopes affords the farther protection derived from the shot glancing off them.

But even the partial recognition of the principle of concealment, the principle of opposing a bank of earth rather than walls of masonry or iron to the tremendous missiles of the present day, flickered and died out; and the War Office, returning to its evil ways, has, within the last few years, erected at enormous cost batteries made as conspicuous as possible, often more than one story high, and has sought to keep out the fire, which these arrangements are calculated to draw, by clothing the batteries with more iron armour, or protecting the embrasures with stronger iron shields; while to make the work of the enemy more easy, and our defence more difficult, the guns have been massed together in the orthodox style, so that but a portion of them are ever likely to come into action, while the men in the whole battery will be "demoralised"-this, we believe, is the technical expression-by a shell bursting in any one of the convenient funnel-shaped openings considerately presented for their reception.

The smoke, likewise, of so many guns is certain to prove most prejudicial to good shooting, and within the forts themselves are generally placed the barracks, which must necessarily soon be reduced to ruin, either by direct or by curved fire, and thus increase the confusion and loss of life in action. No human being, it seems to us, can with impunity stand the constant strain of such conditions on the nervous system. When off work, the garrison of a fort should be safe, their lodging should be secure, their meals should be eaten in peace and security, and the sick and wounded should not be harassed by noise and turmoil. For these reasons the barracks should be at a distance from the battery, and should be hid away out of the enemy's sight, and connected with the battery by covered or screened ways.

In elevated positions, such as are occupied by some of the forts in the Isle of Wight, the natural features of the ground should have been taken advantage of, so as to render them invisible, the guns mounted in open barbette should be painted such a colour as to render them inconspicuous, instead of the uniform black now adopted, and Nature should be allowed to obliterate as much as possible, by the growth of brushwood and grass, the changes which the Engineers may have been compelled to make in the contour of the country. The Inspecting-General and the public generally, would, no doubt, not be able to gaze with delight on the trim slopes, the regular lines, and the frowning cannon, but ample compensation for this will be found in the circumstance that, in time of need, the enemy would be equally at fault.

Again, in coast defences near to the water, the guns, instead of being concentrated, should be dispersed, each gun should have a wide lateral range, the guns should retire out of sight and of exposure, except for the few moments required to lay and fire them. The emplacements should be connected with each other and with the barracks by screened roads, and bomb-proof rooms should be provided for the use of the men on duty when not required to work the guns. The screened roads, having parapets towards the sea, and towards the land also if necessary, would serve the triple purpose of intrenchments, interior lines of communication, and emplacements for light artillery to repel landings.

It may be urged that such work would prove costly on account of the large area of land required, but that would not be the case. The strips of land for roads or military tramways, and the small plots for emplacements, would be as cheaply obtained as for a railway, and by virtue of similar powers ; in most places the cost of land would not be greater than that of armoured structures, the slopes and glacis would be just as available after as before for cultivation, and need not even be purchased, while, if definite plans could at once be adopted for our extensive coasts, a most useful class of work would be available in bad times, such as now press upon us, for the unemployed, and the relief would be widely felt because works are needed all over the kingdom.

The recent experiments at Portland have proved beyond all question that it is next to impossible for a ship at even so small a range as 800 yards, to hit a gun appearing out of a pit for three minutes, when the pit is so arranged, as it is the essential feature of the Moncrieff system that it should be, that its position cannot be detected from the sea. But three minutes is at least six times as long an exposure as is necessary ; indeed, the art of determining the exact position of ships approaching coast batteries has been brought to such perfection that the officer in command of each gun would receive from the observing station messages as to the exact position of the enemy, the training and elevation to be given to the gun, the proper moment for raising it into action, and even, by means of electric fuses, the guns may be fired by the observing officer without risk to a single man, and with an exposure of the guns of less duration than the time required for the flight of a projectile at long range. Contrast such arrangements as these with the open barbette battery at Inchkeith, constructed as if on purpose to offer a conspicuous target, and which recent experiments have proved to be correspondingly vulnerable ; or with the quite recently constructed turret, mounting a roinch gun at Eastbourne, where the projectile of a machinegun disablet the 27-ton cannon, and one shot from a 6 -inch breech-loader knocked off several feet of its barrel.

A careful study of the numerous papers on coast defence read before the United Service Institution, and the discussions, in which many eminent officers of all branches of the service took part, convinces us of the correctness of the views we are maintaining, and the need which exists for laying down organised plans of defence not only for places already protected, but for our long, and in many cases easily accessible, coast-lines. The smoke, which all the speakers agreed in recognising as a great evil in concentrated batteries, would scarcely be any impediment when the guns are scattered, partly because, under most circumstances, the smoke would blow away from each emplacement without obscuring its own gun, or the others, and partly because the observing officer would be above the smoke, and could always make out the enemy.

The smoke itself offers a very feeble indication of the precise locality of the gun which produced it, partly because it is projected a good way from the emplacement at once, partly because the wind in most cases will blow it away to one side or the other. This was fully proved at Portland, when the puffs of smoke sent up as the gun disappeared proved of no assistance to the attack.

But it may be urged, by those unacquainted with the subject, that so formidable a work as raising a heavy gun into the firing position, and checking its recoil and its fall at the same time, would involve cumbersome machinery and the employment of steam or other power. The answer is, that the energy of the discharge itself has been utilised to do all that is required.

The public has been much interested of late in the beautiful mechanism by means of which Mr. Maxim has utilised the energy of recoil, not only to run out the barrel of his gun at every shot, but also to perform all the operations of loading and firing automatically, and that at a rate which almost baffles the imagination. Six hundred shots per minute can be fired without any external power being used. The energy imparted to the shot must have its counterpart in the movement of the gun and carriage in the opposite direction; and Colonel Moncrieff, twenty years ago, showed how, by suitable mechanical arrangements, guns of all sizes could be made to recoil under cover and be raised again into the firing position without the application of external force. There are two systems by which this is accomplished, by means of counter- 
weights and by means of metallic or air springs. In the former case it is easy to see how the counterweight can be so arranged that the work represented by the falling of the gun may be exactly balanced by the work of lifting the balance weight; the energy of recoil, therefore, need only be drawn upon to overcome the friction of the descent and the subsequent friction of ascent, together with the accelerating force necessary to start the gun into smart upward movement. The total amount of work expended in friction does not probably exceed 20 per cent. of the work of raising the gun, and consequently the old muzzle-loaders, with their comparatively small charges and low muzzle velocities of projectile, yield ample power to allow the guns to be lowered completely beyond the reach of hostile shot.

This is a consideration of great importance, because year by year a large number of excellent muzzle-loading guns of all calibres will be returned into store from the Navy, and may at once be utilised for strengthening our coast defences, for they are quite powerful enough to act against unarmoured vessels, light-draught transports, and such like, as well as against the unprotected parts of ironclads; while as howitzers they would be invaluable for preventing landing from boats, and for this service would be quite as effective as the longer, more costly, and more delicately-made breech-loaders, which, however, should be associated with them to resist ironclads. It so happens, also, that the short muzzle-loader is particularly well suited to the Moncrieff carriage, because the men engaged in loading, training, and elevating, working completely under the parapet, are in absolute safety from the enemy's fire, and the only man exposed is he who lays the gun, and even that exposure, as we have already remarked, can often be dispensed with. The muzzle-loaders are also much more simple weapons to manage than the modern, more powerful guns, and would therefore be better fitted for coast batteries, which would undoubtedly have to be manned and worked by Volunteers and men not so highly trained as the Artillery of the regular army.

Some years ago, the War Office definitely adopted the Moncrieff counterweight carriage, and mounted, successfully, guns as large as the 9 -inch of 12 tons weight; but after a time evil counsels prevailed, inveterate prejudice triumphed, and the nation has been saddled with a vast expenditure on forts, which are already obsolete, for by no sort of ingenuity can they be made to carry artillery fitted to cope with that which will be opposed to them. Not that the system was ever rightly applied: Colonel Moncrieff, though attached to the War Department for the express purpose of developing his views, does not appear to have been consulted as to the arrangement of his batteries, or, if consulted, his views were ignored, and the consequence is that, in the case of the comparatively few guns which have been mounted, most of the emplacements are made as conspicuous as possible, and in that way the inestimable advantages of concealment have been thrown away.

The counterweight system, however, becomes very cumbersome when guns exceed some 20 tons in weight. Recourse can then be had to compressed air as a means of storing the energy of recoil. But the work done in compressing air reveals itself in the form of heat, which raises its temperature, and is slowly dissipated as it cools. Again, the air, in expanding to raise the gun, is cooled by the amount of heat converted into work, and its pressure is thereby reduced, so that the losses on these two accounts, added to the somewhat increased friction of the machinery, set a limit to the height to which the stored energy of recoil can raise the gun: the increased charges used in modern artillery, however, compensate for these losses, and it is possible by hydro-pneumatic arrangement to give efficient cover to the heaviest guns. The natural fear arises lest the introduction of water and compressed air may not add elements of danger in the facility with which dirt and debris, not sufficient to injure an ordinary mounting, may affect the more complicated arrangement. There is no doubt that a breechloading gun requires more care in its use than a muzzleloader, and a hydro-pneumatic mounting is not so simple as a carriage with an ordinary friction or hydraulic compressor, but experience with the 6-inch hydropneumatic siege carriage has shown that the system is capable of enduring very rough usage, and is by no means easily deranged.

The Australian colonies, acting under the advice of the late General Scratchley and General Steward, seem to be more intelligent and far-seeing than the mother country, and have acquired a considerable number of breech-loading guns, mounted on the system recommended, and carried out completely in all its details. It is difficult to see how official opposition can long brave the assaults made on it by common-sense, and the glaring defects of the old methods.

(To be continued.)

\section{THE TEMPERATURE OF THE CLYDE $S E A-A R E A$.}

\section{I.}

T $N$ the spring of $\mathrm{I} 886$ a regular system of temperature observations was commenced in the water of the Clyde sea-area, by the staff of the Scottish Marine Station, under the personal superintendence of Mr. John Murray of the Challenger Commission. The work has since proceeded steadily, and will probably be continued to the close of the present year. Previous to 1886, few temperature observations had been recorded dealing with the deep water on the west coast of Scotland ; these were almost entirely the work of Mr. J. Y. Buchanan on occasional summer cruises.

The scope of the present investigation is limited chiefly by the capabilities of the Marine Station's steam-yacht Medusa. She is a vessel of 30 tons, yacht measurement, steaming 6 knots in ordinary circumstances; but not adapted for working amongst the tremendous tidal currents of the North Channel except in the calmest weather. On the other hand, her small size, and the convenient arrangement of a steam-winch for working the sounding-line enables observations to be made with great rapidity in quiet water. Inside of Cantyre, soundings have been obtained in almost every kind of weather, and the present article will deal with this part of the west coast only.

The Clyde sea-area ${ }^{1}$ comprises all the connected watersystem, I 300 square miles in extent, lying to the north of a line drawn from the Mull of Cantyre to Corsewall Point in Wigtownshire. This line corresponds nearly to the 50-fathom contour ; outside it the depth increases rapidly to over 80 fathoms; towards the inner or northern side it diminishes at first, and then remains at about 27 fathoms over an area of 270 square miles. This bank is termed the Clyde Barrier Plateau; it crosses from Cantyre to Ayrshire, past the south end of Arran, and around Ailsa Craig. The shallowest water covers a ridge at a depth of about 20 fathoms from the surface. The water deepens on the inside of the Plateau to form the Arran Basin, which in form resembles the letter $\lambda$, surrounding Arran on the west, east, and north, and running up into Lower Loch Fyne. The depth in this basin exceeds 50 fathoms over roo square miles; the deepest water, IO7 fathoms, occurs off Skate Island, near Tarbert. A much smaller depression runs in a straight line from the Cumbraes to Dog Rock at the mouth of Loch Goil. It is known as the Dunoon Basin, and has an average depth of 40 fathoms and a maximum of 56 . Of the numerous lochs, reference will be made to two only, Upper Loch Fyne and Loch Goil. The former measures 25 miles from Otter Ferry to the head; it consists of a basin 30 fathoms deep, bounded by channels having an

x For detailed description and map see Scottish Geographical Magazine for January I 887 . 